\title{
Role of Focused Assessment with Sonography for Trauma in the Assessment of Blunt Abdominal Trauma - A Review
}

\author{
Sushanth Ramanath Nayak ${ }^{1}$, Meenakshi Pate Yeolaㄹ, Samatha Ramanath Nayak ${ }^{3}$, \\ Kratika Kamath ${ }^{4}$, Pratikshit Singh Raghuwanshi ${ }^{5}$
}

1, 2, 3, 5 Department of Surgery, Jawaharlal Nehru Medical College, Sawangi, Wardha, Maharashtra, India. ${ }^{4}$ Department of Obstetrics and Gynaecology, Sri Devaraj Urs Academy of Higher Education and Research, Kolar, Karnataka, India.

\section{ABSTRACT}

Focused assessment with sonography for trauma (FAST), is the sonographic examination of the abdomen and pelvis for the detection of presence of free fluid in intraperitoneal or pericardial region. Blunt abdominal trauma is one of the most common causes of all injuries. Blunt abdominal trauma is usually not obvious. Hence, often missed, unless, repeatedly looked for. Due to the delay in diagnosis and inadequate treatment of the abdominal injuries, most of the cases are fatal. Knowledge about the management of blunt abdominal trauma has progressively increased. Despite the best techniques and advances in diagnostic and supportive care, morbidity and mortality remain high. This could be due to the interval between trauma and hospitalization, inadequate and lack of appropriate surgical treatment, delay in diagnosis, postoperative complications and associated trauma specially to head, thorax and pelvis.

In cases of blunt trauma to the abdomen (BTA), free fluid is generally because of haemorrhage and spilled bowel contents or both; contributing to grave life deceiving conditions and is an important milestone in taking swift action directed towards the need for any critical intervention. FAST is found to be a diagnostic tool initially to detect intra-abdominal fluid in abdominal trauma.

With proper training and understanding of the limitations of ultrasound, good results from FAST can be obtained. Patients with a positive FAST are at risk for significant abdominal bleeding that is critical and likely to need laparotomy sooner.

The specificity of the FAST is highly dependent on the experience of the person conducting the examination and hence placing the person examining in a major role in determining the need for an emergency intervention. The results of FAST have been both a boon and a curse in deciding the need for further interventions. Situations, where the results have been overlooked, have sometimes proven to be a cause for delay in the management and sometimes have proved have a situational advantage by going for a better radiological investigation like CT (Computed Tomography) scan.

The objective of this review article is to study the impact of FAST on blunt trauma abdomen in the management in emergencies. The routine FAST examination doesn't show any extra benefit in hastening the clinical decision making. While controversy remains, decision of using FAST is left to the individual surgeons' choice in the emergency department.

\section{KEY WORDS}

Focused Abdominal Sonography, Blunt Abdomen Trauma, Diagnostic Accuracy, Haemoperitoneum, Emergency, FAST, Free Fluid
Corresponding Author: Dr. Meenakshi Pate Yeola, Department of Surgery, Jawaharlal Nehru Medical College, Sawangi, Wardha,

Maharashtra, India.

E-mail:drmeenu7@rediff.com

DOI: $10.14260 /$ jemds/2021/9

How to Cite This Article: Nayak SR, Yeola MP, Nayak SR, et al. Role of focused assessment with sonography for trauma in the assessment of blunt abdominal trauma. J Evolution Med Dent Sci 2021;10(01):45-50, DOI: $10.14260 /$ jemds $/ 2021 / 9$

Submission 12-08-2020,

Peer Review 07-10-2020,

Acceptance 12-10-2020,

Published 04-01-2021.

Copyright (C) 2021 Sushanth Ramanath Nayak et al. This is an open-access article distributed under Creative Commons Attribution License [Attribution 4.0 International (CC BY 4.0)] 


\section{BACKGROUND}

Since the 1970s, various studies have been used to describe the evaluation of abdominal trauma using ultrasound. However, it was after the 1990s that sonographic examination was taken into consideration for critical emergencies. 'FAST' (focused assessment with sonography for trauma), was termed for ultrasonographic evaluation of trauma, by Rozycki and colleagues in 1996, which has remained an acronym since then; the use of FAST in blunt abdominal trauma patients, since then, has been considered as the most important advancement in the initial evaluation. ${ }^{1}$

It takes around $3-5$ minutes to finish the FAST examination and it consists of 4 to 6 views. The views include 3 to 5 intra-abdominal and one cardiac with the rationale of identification of peritoneal or pericardial fluid. FAST was originally used to detect free intraperitoneal fluid and later on from being an accessory in the screening investigations, it became a diagnostic tool for the sake of reducing the cost and promoting non-invasive methods. ${ }^{1}$

The rate of abdominal injury is $20 \%$ of all injury cases, and the relative rate of blunt / penetrating abdominal injury varies concurring on the geographic region. In urban regions, the rate of gunfire and cut wounds (penetrating wounds) is higher than blunt injury, and the inverse is the case in country areas. Blunt wounds to the abdomen are most common following road activity crashes and drop from heights and often pose symptomatic and management challenges. The rapid diagnosis and suitable and convenient management mediation of these patients are the fundamental basics to maintain a strategic distance from noteworthy morbidity and mortality related to a delay in the treatment. The most imperative figure within the administration of blunt abdominal injury may be a triage of the patients who require prompt laparotomy or observation only. The history and physical examination may be untrustworthy because of different variables. No single examination has been found to precisely distinguish patients who require prompt laparotomy. ${ }^{2}$

The role of FAST in surveying the abdomen in stable blunt trauma patients is as of now vague, due to a wide extent of reported sensitivities in diagnosing intraperitoneal injury (42 - $87 \%$ ). Computed tomography is well established for assessing abdominal solid organ damage after blunt trauma, particularly in high hazard patients with pelvic fractures, gross haematuria and lower rib fractures. The use of ultrasound has been constrained in stable patients due to the inability of ultrasound to assess the retroperitoneum, hard structures, and parenchymal wounds without haemoperitoneum. The affectability of FAST to identify intraperitoneal damage is directly related to the reality that FAST depends on the presence of free intraperitoneal blood and does not routinely include parenchymal imaging. The capacity of FAST to detect intra-abdominal damage may be restricted by the detailed need of significant haemoperitoneum upon affirmation in patients with intra-abdominal strong organ injury. ${ }^{3}$

In the paediatric age group, BTA is the most common mode of injury to the abdomen in which the CT scan is the prime modality for imaging. In the adult age group, depending on the haemodynamic stability, FAST is used to decipher the abdominal fluid and also, help in the categorizing of the patients for the sake of further imaging or any surgical intervention. 4
Usage of Diagnostic Peritoneal Lavage (DPL) in the investigative profile of trauma in the abdomen for free lying fluid has been changed by the entry of FAST; the advantage of FAST being non-invasiveness, easily repeatable, and nonintruding investigation. However, the function of FAST in paediatric trauma stays a topic of controversy. 4

This study hasn't been conducted to recommend that FAST examination should supplant CT scan to diagnose the intraabdominal injury, but to assess whether or not FAST examination can be utilized as an instrument to anticipate administration in blunt abdominal trauma patients. 5

Evaluation of the unstable blunt trauma patient requires rapid clinical assessment to initiate appropriate therapeutic interventions. The FAST examination is an important and rapid assessment tool that can reliably detect haemoperitoneum in the hands of a trained surgeon. The utility of the FAST in patients with complex pelvic fractures has been reported to be unreliable. Sensitivity for haemoperitoneum in the setting of a pelvic fracture has been reported to be as low as $26 \%$. In the haemodynamically unstable polytrauma patient, delineation of intra-abdominal haemorrhage versus pelvic fracture-related haemorrhage can impact clinical decision making. ${ }^{6}$

\section{METHODS}

A precise survey of the literature has been performed for a particular inquiry in Medline and PubMed up to June 2020. Reference arrangements of recovered articles and review articles were physically looked for utilizing the search terms "Focused Abdominal Sonography", "Blunt Abdomen Trauma", "Diagnostic Accuracy", "Haemoperitoneum", "Emergency", "FAST" or "Free Fluid". A collective review of these studies regarding the effectiveness of FAST in patients of abdominal trauma has been done, its findings \& limitations have been discussed and its conclusion noted in this review article

\section{Technique}

Most of the research of FAST has radiologists conducting the ultrasonography. This includes the requirement of off-site personnel and at times it requires shifting a trauma patient to the radiology section. A Study conducted by S.V.S. Soundappan et al. suggest that surgeons were able to carry out an acceptable focused scan following a brief duration of schooling only. ${ }^{4}$ In the study done by McCarter et al. pointed out that extensive didactic training and high volumes of examination might not be to overcome the learning curve for FAST for trauma surgeons. With the clinical experience with this modality of FAST Surgeons gained an accuracy of $90 \%{ }^{4}$

According to the study conducted by Buzzas et al., it was observed that residents of surgery were able to perform the FAST scan safely when compared to radiologists. This study made a point that not only FAST could be cost saving but has to be a regular part of the complete evaluation of trauma patients in the surgery department when done by the surgeons and the sensitivity of FAST here was $80 \%{ }^{4}$

A study by Nicole et al. uses this dynamic evaluation toolrepeat evaluation in the unstable patient is critical. It is recognized that the initial FAST may be negative only later on turn to positive, once a minimum of $200-250 \mathrm{cc}$ of blood 
accumulates in the abdomen. In haemodynamically unstable patients, the FAST must be repeated to ensure clinically significant haemoperitoneum has not developed.

\section{Patient Position}

The preferred position of examination for trauma patients is supine. The other positions like Trendelenburg, reverse Trendelenburg, and decubitus may facilitate pooling of free fluid in the dependent regions, thereby potentially increasing the detection yield, and should be done only if the clinical scenario permits. ${ }^{1}$

\section{Transducer}

Transducer selection depends on the built of the patient and for average built adult, the sound wave penetration should be at least $20 \mathrm{~cm}, 3.5$ to $5 \mathrm{MHz}$ transducers are selected. ${ }^{1}$

\section{Fast Examination Views}

FAST examination includes 4 to 6 views as follows

1. Transverse sub xiphoid

2. Longitudinal Right Upper Quadrant

3. Longitudinal Left Upper Quadrant

4. Right Lateral

5. Left Lateral

6. Longitudinal, transverse pelvis as depicted
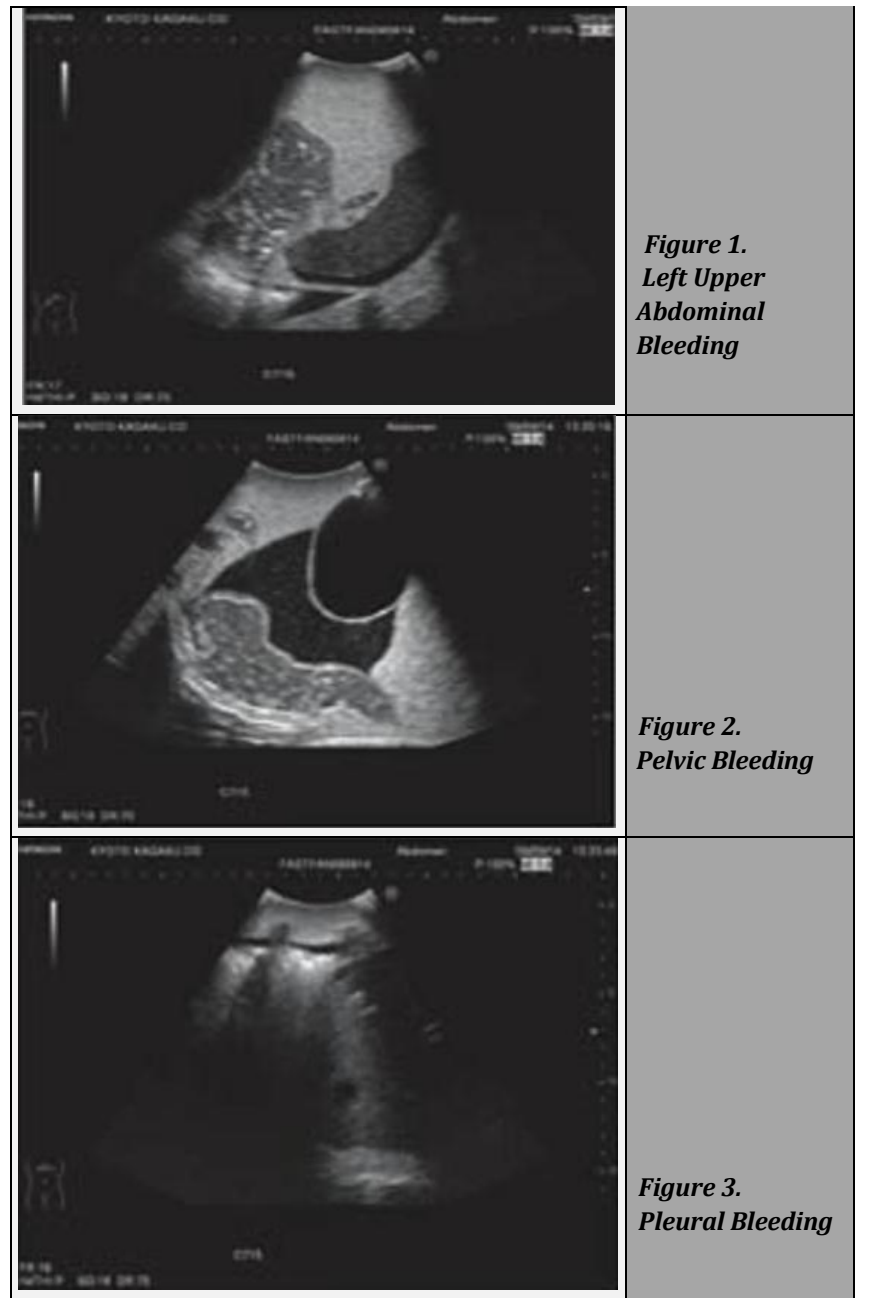

Figure 2.

Pelvic Bleeding

Figure 3.

Pleural Bleeding
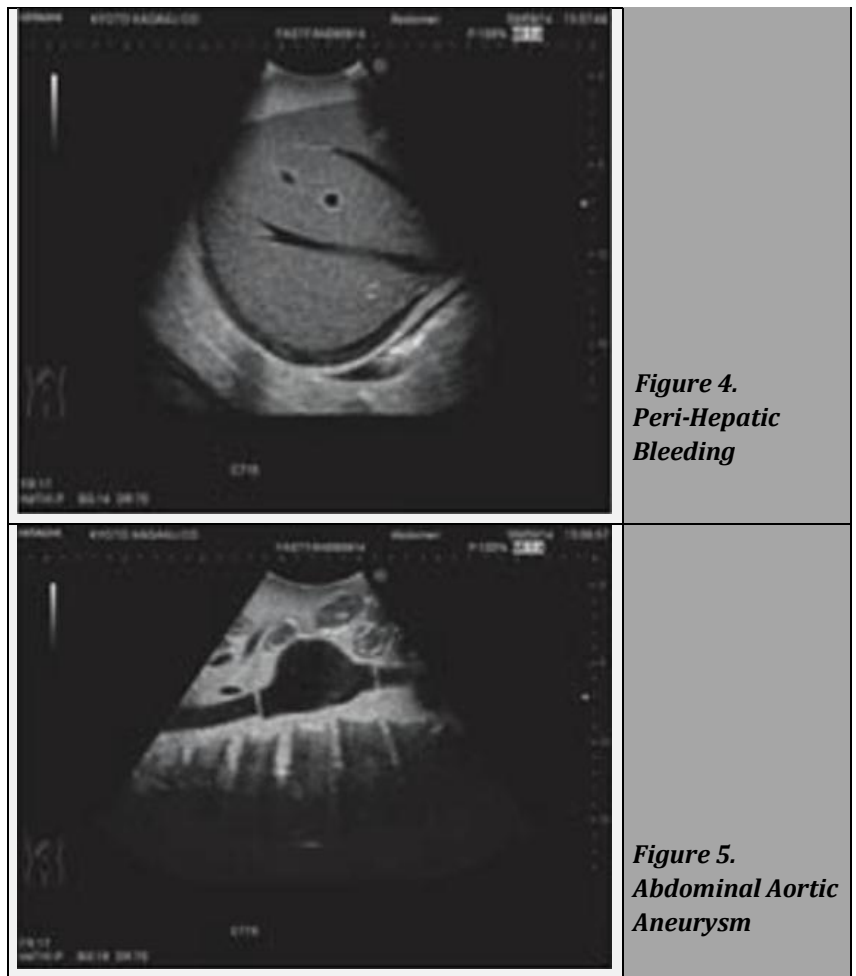

Figure 5.

Abdominal Aortic Aneurysm

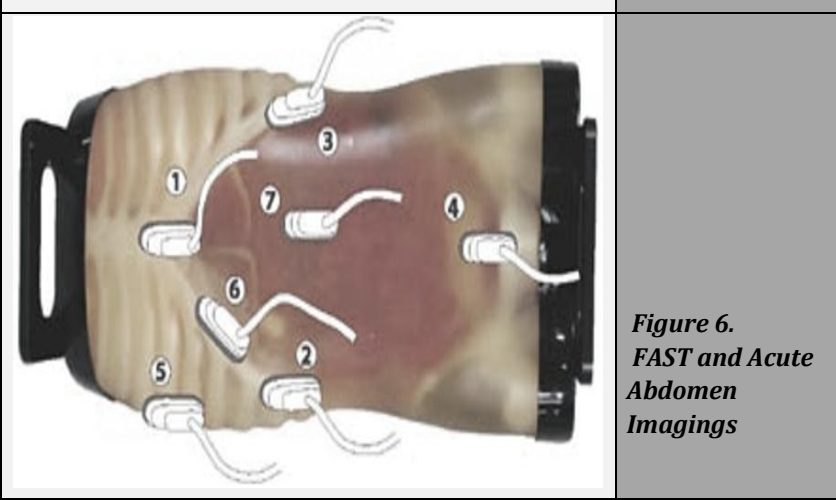

DISCUSSION

The most common reason for death during the first 40 years of life is considered to be trauma, which can lead to life-long disability causing loss of the important period in the youth generation. ${ }^{7}$ Blunt trauma abdomen always poses diagnostic as well as a management challenge. The quick finding and suitable convenient mediation of BTA patients are consistently fundamental to evade noteworthy morbidity and mortality related to delay in the forthcoming decisions. ${ }^{8}$ Blunt trauma abdomen patients' evaluation, history, and physical examination may not be reliable and the blunt abdominal trauma investigation available in the emergency department may not be sufficient in identifying the patients who will be requiring immediate laparotomy. The prime factor in the management of blunt trauma to the abdomen is the triage regarding conservative management of emergency exploration of the patient. ${ }^{1}$ For this, a quick, secure, successful, dependable, and reproducible examination is required for the essential screening of intraperitoneal haemorrhage or intraabdominal damage. To satisfy all these criteria, FAST is one of the foremost favoured bedside examinations to be taken as an expansion of the physical examination of the patient with blunt trauma abdomen which can be performed amid a revival of the 
patients, but, this thought will be after disregarding the included flawed collateral negatives which come together with the choice considering FAST as an imperative marker within the calculation of BTA administration. ${ }^{9}$

To understand the characteristic part of FAST in blunt trauma abdomen injuries, a collective generalized analysis \& outcome discussion has been done regarding studies that have discussed the diagnostic accuracy of FAST and hence, the clinical decisions made. ${ }^{9}$ A study was conducted by Subodh Kumar et al. for accuracy of FAST in blunt trauma abdomen wherein, FAST was compared to contrast-enhanced computed tomography (CECT) findings for abdominal free fluid, and the overall findings for the affectability, specificity, and precision of FAST were 77.3, 100 and 79.2 percent respectively. ${ }^{2}$

The study was conducted by Richards et al. for Blunt Trauma Abdomen patients in which 3,264 patients underwent FAST in the emergency department and the findings of which were compared with CECT, intraoperative findings, and clinical outcomes. The affectability, specificity, and precision of FAST were 60,98 , and $80 \%$, respectively, for diagnosing free intraperitoneal fluid. In the study done by Adams et al. ${ }^{16}$ for recognizing intra-abdominal injuries in adults for the FAST has $82 \%$ sensitivity and $99 \%$ specificity respectively. A similar study done by Fleming et al. ${ }^{17}$ in which the analysts concluded that FAST had a specificity of $94.7 \%$ [95 \% certainty interim (CI), 0.75 - 0.99), affectability of $46.2 \%$ (95\% CI, 0.33 - 0.60), positive prescient value of $0.96(0.81-0.99)$, and negative prescient value of $0.39(0.26-0.54){ }^{1}$

It remains questionable, the character of FAST in paediatric trauma. As most of the studies of the role of FAST in blunt trauma abdomen in paediatric patients, the radiologists are doing the investigation. It requires the availability of an offsite faculty in the emergency department or shifting of the paediatric patient to the radiology patient. Subsequently, The Australian Injury Society has suggested that critical ultrasound ought to be accessible within the critical division for appraisal of all trauma casualties even though typically it is still not a schedule practiced in most paediatric centers. ${ }^{4}$

Negating to it the imminent study conducted by Coley et al.18 concluded that FAST may not be utilized to appraise the patient management because of its destitute affectability and negative prescient value. In that study, they included the steady patients who experienced CECT examination, the larger part of whom had a typical CT. Their conclusions were best on the reality that ultrasonography within the shape of FAST doesn't illustrate strong organ damage without free fluid. So, in steady patients, in case, there are abdominal signs CT ought to be performed to avoid the intra-abdominal wounds and FAST is as it were, only a screening test for appraisal of free fluid and not implied to supplant the clinical examination or other radiological examinations. ${ }^{4}$ The study conducted by Bennett et al., evaluated the value of FAST in children after blunt trauma abdomen to identify intra-abdominal injuries (IAI) and intra-abdominal injuries requiring acute intervention (IAI-I). We found that FAST had limited sensitivity to screen the intra-abdominal injury in children experiencing blunt trauma abdomen and when performed less occasionally changed the course of management. Further, they also identified a significant variation in the use of FAST among trauma for paediatric centers. Contrary to adults, usage of FAST sonography in paediatric trauma remains questionable. Initial studies showed favourable test characteristics with

\begin{tabular}{|c|c|c|c|c|c|}
\hline $\begin{array}{l}\ddot{0} \\
\dot{m}\end{array}$ & 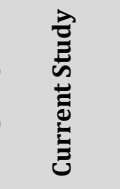 & 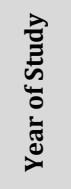 & 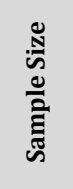 & 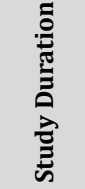 & 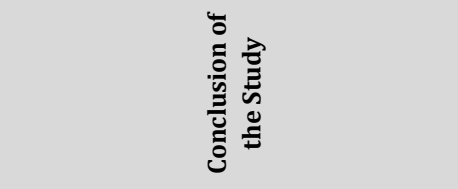 \\
\hline 1. & $\begin{array}{l}\text { Brett C. Lee } \\
\text { et al. }\end{array}$ & 2006 & 4,029 & 6 years & $\begin{array}{l}\text { Hypotensive patients screened within the crisis } \\
\text { division with positive FAST discoveries may be } \\
\text { triaged straightforwardly to therapeutic } \\
\text { laparotomy, depending on the outcomes of the FAST } \\
\text { examination. } .^{10}\end{array}$ \\
\hline 2. & $\begin{array}{l}\text { S. Kumar et } \\
\text { al. }\end{array}$ & 2013 & 50 & 3 years & $\begin{array}{l}\text { Fast could bean attainable examination in patients } \\
\text { with BTA, and it can be performed effortlessly and } \\
\text { rapidly within the emergency room with a sensible } \\
\text { affectability, specificity, and exactness. It makes a } \\
\text { difference within the introductory triage of patients } \\
\text { for conservative management or quick operation. }\end{array}$ \\
\hline 3. & $\begin{array}{l}\text { Nirav Y. } \\
\text { Patel et al. }\end{array}$ & 2008 & 200 & 2 years & $\begin{array}{c}\text { Fast is an important aide within the administration } \\
\text { of abdominal injury when utilized specifically } \\
\text { based on a combination of hemodynamic status and } \\
\text { clinical discoveries }{ }^{1}\end{array}$ \\
\hline 4. & $\begin{array}{l}\text { S.V.S. } \\
\text { Soundappa } \\
\text { netal. }\end{array}$ & 2005 & 85 & 1 year & $\begin{array}{l}\text { Fast may be a possibly important apparatus within } \\
\text { the assessment of paediatric blunt injury casualties } \\
\text { for free fluid inside the peritoneal cavity. }\end{array}$ \\
\hline 5. & $\begin{array}{l}\text { MichalleSo } \\
\text { udack et al. }\end{array}$ & 2003 & 313 & $\begin{array}{c}1.5 \\
\text { years }\end{array}$ & $\begin{array}{l}\text { Fast is a viable instrument in screening paediatric } \\
\text { injury patients for blunt stomach injury.11 }\end{array}$ \\
\hline 6. & $\begin{array}{l}\text { Nicole } \\
\text { Townsend } \\
\text { Christian et } \\
\text { al. }\end{array}$ & 2017 & 81 & $\begin{array}{c}10 \\
\text { years }\end{array}$ & $\begin{array}{l}\text { Fast dependably distinguishes clinically critical } \\
\text { hemoperitoneum in life-threatening, pelvic fracture- } \\
\text { related haemorrhage }{ }^{12}\end{array}$ \\
\hline 7. & $\begin{array}{l}\text { Jeremy M. } \\
\text { Hsu etal. }\end{array}$ & 2006 & 463 & 5 years & $\begin{array}{l}\text { The study illustrates that the utilization of non- } \\
\text { radiologists performed Fast within the location of } \\
\text { free fluid is secure and precise inside an Australian } \\
\text { Injury Centre }\end{array}$ \\
\hline 8. & $\begin{array}{l}\text { Paul } \\
\text { McGaha et } \\
\text { al. }\end{array}$ & 2018 & 1008 & 3 years & $\begin{array}{l}\text { Negative Fast is prescient of effective Nonoperative } \\
\text { management of paediatric Blunt liver and spleen } \\
\text { injury. }\end{array}$ \\
\hline 9. & $\begin{array}{l}\text { Alexander } \\
\text { Becker et } \\
\text { al. }\end{array}$ & 2009 & 3181 & 5 years & $\begin{array}{l}\text { Patients with high Injury Severity Scoring are at } \\
\text { expanded chance of having ultrasound-masked } \\
\text { wounds and have a lower precision of their } \\
\text { ultrasound Injury Severity Score examination than } \\
\text { patients with low and direct Injury Severity Score }{ }^{13}\end{array}$ \\
\hline & $\begin{array}{l}\text { Lorne H. } \\
\text { Blackbour } \\
\text { ne etal. }\end{array}$ & 2004 & 547 & 1 year & $\begin{array}{c}\text { Auxiliary ultrasound will increment the affectability } \\
\text { of ultrasound to distinguish Intraperitoneal harm } \\
\text { and will run the show out of clinically noteworthy } \\
\text { hemoperitoneum. }\end{array}$ \\
\hline 11. & $\begin{array}{l}\text { J. Christian } \\
\text { Foxet al. }\end{array}$ & 2010 & 431 & 4 years & $\begin{array}{c}\text { Fast encompasses a low affectability for clinically } \\
\text { vital Intraperitoneal free fluid but has high } \\
\text { specificity }{ }^{12}\end{array}$ \\
\hline 12. & $\begin{array}{l}\text { Jeffrey W. } \\
\text { Carter et al. }\end{array}$ & 2014 & 1671 & $\begin{array}{c}1.5 \\
\text { years }\end{array}$ & $\begin{array}{l}\text { Fast incorporates an exceptional low affectability in } \\
\text { recognizing limit intraabdominal damage. In } \\
\text { hemodynamically steady patients, a negative Fast } \\
\text { without a CT may result in missed intra-abdominal } \\
\text { injuries. }{ }^{6}\end{array}$ \\
\hline 13. & $\begin{array}{l}\text { Bala } \\
\text { Natarajan } \\
\text { et al. }\end{array}$ & 2010 & 2980 & 7 years & $\begin{array}{l}\text { Given the low affectability, a negative focused } \\
\text { evaluation with sonography for injury without } \\
\text { confirmation by computerized tomography may } \\
\text { result in missed intra-abdominal injuries. }{ }^{9}\end{array}$ \\
\hline & $\begin{array}{l}\text { BennettW. } \\
\text { Calder et al. }\end{array}$ & 2017 & 2188 & 1 year & $\begin{array}{l}\text { Fast encompasses a low affectability for Intra- } \\
\text { abdominal wounds, misses Intra-abdominal injuries } \\
\text { requiring intense intercession, and occasionally } \\
\text { impacts administration in paediatric Blunt } \\
\text { Abdomen Injury. }{ }^{14}\end{array}$ \\
\hline & $\begin{array}{c}\text { Lance } \\
\text { Hoffman et } \\
\text { al. }\end{array}$ & 2009 & 458 & 6 years & $\begin{array}{l}\text { The nearness of a pelvic fracture or renal damage in } \\
\text { grown-up casualties of blunt abdominal trauma } \\
\text { increments the proportion of the chances that a Fast } \\
\text { examination without proof of an irregular fluid } \\
\text { collection may speak to a negative ultrasound. }{ }^{15}\end{array}$ \\
\hline \multicolumn{6}{|c|}{$\begin{array}{c}\text { Comparison of Various Studies Regarding Role of FAST in Assessment } \\
\text { of Blunt Abdominal Trauma }\end{array}$} \\
\hline
\end{tabular}


sensitivity, specificity, and accuracy of FAST for IAI of $90.9 \%$, $83.6 \%$, and $84.3 \%$, respectively.

Subsequent studies on FAST performed in children varied in findings. Some showed significantly decreased sensitivity $33 \%$ to $55 \%$ but consistently high specificity of $83 \%$ to $95 \%$ of FAST, suggesting FAST was not an effective screening modality. In contrast, others showed much higher sensitivity and specificity suggesting that FAST is an effective screening tool after blunt abdominal trauma. A meta-analysis of 25 articles counting 3,838 paediatric patients appeared pooled test characteristics of the following: affectability, $80 \%$ (95\% CI, 76 - $84 \%$ ); specificity, $96 \%$ (95\% CI, 95 - $97 \%$ ); positive probability proportion, 22.9 (95\% CI, 17.2 - 30.5); and negative probability proportion, $0.2(95 \% \mathrm{CI}, 0.16-0.25) .^{14}$ There was a notable decrease in sensitivity when only levels 1 and 2 evidence were reviewed. One of the limitations of FAST in detecting IAI in children is that at least $37 \%$ of IAI are not associated with free fluid. One of the most important potential benefits of FAST is to rapidly identify patients who present with hypotension secondary to intra-abdominal haemorrhage. In our study, the accuracy of FAST was lower in patients with hypotension (61.5 \%) vs. those with normal BP (Blood Pressure) on arrival (73.7 \%) although there were very few patients that presented with hypotension for age. Also, we found that FAST was no more accurate in the subset of patients with abnormal abdominal examinations or lower GCS (Glasgow Coma Scale) than those with normal abdominal examinations and higher GCS score. In our study, FAST had improved accuracy in those patients who were less injured (ISS $<16$ ) as compared to those with a higher Injury Severity Score (ISS) ( $80.6 \%$ vs. $54.6 \%$ ). This may be explained by the fact that demonstrative precision is influenced by illness predominance. As infection predominance diminishes, demonstrative exactness increments at the same affectability and specificity possibly clarifying the appearance of expanded precision of FAST in patients with more ISS where IAI is amazingly uncommon.

Hence, after review, we can conclude that the advantages of FAST are as it is portable, non-invasive, accessible, conducted bedside, cost-effective, lack of exposure to radiation, real-time imaging, multiplanar capability, and serial application. The disadvantages of FAST are: it is operator dependant; it depends on patient habitus, is the specific identification of injury may not be possible and has poor penetration through the air. The quality of sonography evaluation isn't a mere devise-based outcome but also a huge technique dependant factor, involving the proficiency of the sonographer too. Repeated exposure of the surgeon to the intrathoracic and intra-abdominal injuries will prove to be provocative not only as a sonographer with learned techniques to conduct the investigation but also as a mode to recognize minimal to minute intra-abdominal pathologies and conditions causing the deterioration of the clinical status of the patient. Though the detection of intra-abdominal and intrathoracic injury is a tedious job and requires quite good experience, quick detection of the free fluid and a quick examination in the emergency room would help in the hastening of the management of the patient. ${ }^{19}$

Despite having multiple types of research proving the usage of FAST in the assessment of patients with blunt trauma abdomen not to be reliable enough to decide further decision or even shown to be time consuming in various scenarios such as paediatric blunt abdominal trauma, patients with multiple injuries, penetrating injuries, bowel injuries, pelvic fractures, etc., many surgeons are fearing that the abandonment of routine FAST in cases of blunt abdominal trauma would not be a safe option to maintain a required mode of management and line of treatment.

\section{Summary}

Ultrasonographic imaging could be a non-invasive, reasonable, and promptly accessible instrument at the patient's side. Thus, at numerous establishments, it has fundamentally supplanted diagnostic peritoneal lavage for the discovery of intraperitoneal fluid. In cases where there are experienced hands involved, the FAST examination has been appeared to be both delicate and in the location of haemoperitoneum in casualties of blunt abdominal injury. ${ }^{15}$

The review of the studies conducted shows that the usage of FAST in blunt abdominal trauma as an emergency modality does help in speeding up the clinical decision making, but, some researches have shown that there are many factors which support the intended opinion that wastage of time in carrying out FAST will not only slow down the required speed of managing the patient but also prove to be additional collateral damage in the wellbeing of the patient.

For a few surgeons, the principal motive of using FAST is to rule out intraperitoneal free fluid, intrathoracic injury and to evaluate the severity of damage caused. Haemodynamically stable patients experiencing blunt trauma to the abdomen are to be assessed at the earliest and their further steps of management are to be determined very fast.

\section{CONCLUSIONS}

Routine use of FAST shows no specific benefit in hastening the management of blunt abdominal trauma or any surgical benefit for the same. Be that as it may, based on the accessible literature, the authors accept that there has not been adequate proof to deny the utilization of FAST and assessment is required for the same.

Financial or other competing interests: None.

Disclosure forms provided by the authors are available with the full text of this article at jemds.com.

\section{REFERENCES}

[1] Patel NY, Riherd JM. Focused assessment with sonography for trauma: methods, accuracy, and indications. Surg Clin North Am 2011;91(1):195-207.

[2] Kumar S, Bansal VK, Muduly DK, et al. Accuracy of focused assessment with sonography for trauma (FAST) in blunt trauma abdomen-a prospective study. Indian J Surg 2015;77(Suppl 2):393-7.

[3] Blackbourne LH, Soffer D, McKenney M, et al. Secondary ultrasound examination increases the sensitivity of the FAST exam in blunt trauma. J Trauma 2004;57(5):934-8.

[4] Soundappan SVS, Holland AJA, Cass DT, et al. Diagnostic accuracy of surgeon-performed focused abdominal 
sonography (FAST) in blunt pediatric trauma. Injury 2005;36(8):970-5.

[5] McGaha P, Motghare P, Sarwar Z, et al. Negative focused abdominal sonography for trauma examination predicts successful nonoperative management in pediatric solid organ injury: a prospective Arizona-texas-OklahomaMemphis-Arkansas + consortium study. J Trauma Acute Care Surg 2019;86(1):86-91.

[6] Carter JW, Falco MH, Chopko MS, et al. Do we rely on fast for decision-making in the management of blunt abdominal trauma? Injury 2015;46(5):817-21.

[7] Baker S, Baker SP, Ginsburg MJ, et al. The injury factbook. USA: Oxford University Press 1992.

[8] Hsu JM, Joseph AP, Tarlinton LJ, et al. The accuracy of focused assessment with sonography in trauma (FAST) in blunt trauma patients: the experience of an Australian major trauma service. Injury 2007;38(1):71-5.

[9] Natarajan B, Gupta PK, Cemaj S, et al. FAST scan: is it worth doing in hemodynamically stable blunt trauma patients? Surgery 2010;148(4):695-701.

[10] Lee BC, Ormsby EL, McGahan JP, et al. The utility of sonography for the triage of blunt abdominal trauma patients to exploratory laparotomy. Am J Roentgenol 2007;188(2):415-21.

[11] Soudack M, Epelman M, Maor R, et al. Experience with focused abdominal sonography for trauma (FAST) in 313 pediatric patients. J Clin Ultrasound 2004;32(2):53-61.

[12] Christian NT, Burlew CC, Moore EE, et al. The focused abdominal sonography for trauma examination can reliably identify patients with significant intra-abdominal hemorrhage in life-threatening pelvic fractures. J Trauma Acute Care Surg 2018;84(6):924-8.

[13] Becker A, Lin G, McKenney MG, et al. Is the FAST exam reliable in severely injured patients? Injury 2010;41(5):479-83.

[14] Calder BW, Vogel AM, Zhang J, et al. Focused assessment with sonography for trauma in children after blunt abdominal trauma: a multi-institutional analysis. J Trauma Acute Care Surg 2017;83(2):218-24.

[15] Hoffman L, Pierce D, Puumala S. Clinical predictors of injuries not identified by focused abdominal sonogram for trauma (FAST) examinations. J Emerg Med 2009;36(3):271-9.

[16] Adams B, Sisson C. ACP Journal Club: review: bedside ultrasonography has $82 \%$ sensitivity and $99 \%$ specificity for blunt intraabdominal injury. Ann Intern Med 2012;157(4): JC2-12.

[17] Fleming S, Bird R, Ratnasingham K, et al. Accuracy of FAST scan in blunt abdominal trauma in a major London trauma center. Crit Care 2013;17(Suppl 2): P290.

[18] Coley BD, Mutabagani KH, Martin LC, et al. Focused abdominal sonography for trauma (FAST) in children with blunt abdominal trauma. J Trauma 2000;48(5):9026.

[19] Röthlin MA, Näf R, Amgwerd M, et al. Ultrasound in blunt abdominal and thoracic trauma. J Trauma 1993;34(4)488-95. 